PALABRAS CLAVE

Azúcar

Alcohol

Combustibles de alcohol

Desarrollo industrial

Producción agrícola

Producción industrial

Innovaciones

Competitividad

Brasil
Eduardo Strachman

Profesor Asistente Doctor del

Departamento de Economía y

Coordinador del Programa de posgrado

en economía de la Facultad de Ciencias

y Letras, Campus de Araraquara,

Universidad Estadual Paulista

"Júlio de Mesquita Filho" (UNESP)

edstrach@fclar.unesp.br

Gustavo Milan Pupin

Licenciado en Ciencias Económicas,

Facultad de Ciencias y Letras,

Campus de Araraquara,

Universidad Estadual Paulista

"Júlio de Mesquita Filho" (UNESP)

œ gustavopupin@gmail.com
REVISTA CEPAL 103 • ABRIL 2011

\section{El sector brasileño del azúcar y el alcohol: evolución, cadena productiva e innovaciones}

\author{
Eduardo Strachman y Gustavo Milan Pupin
}

$\mathrm{E}$

sector del azúcar y el alcohol es uno de los de mayor crecimiento y desarrollo en el Brasil, aunque algunos especialistas temen sin fundamento que el cultivo de caña de azúcar sustituya a las plantaciones de alimentos. Aquí se examina cómo el Brasil y el estado de São Paulo se convirtieron en importantes actores en ese sector y se expone una teoría sobre la relevancia de las innovaciones en el aumento de la competitividad, la productividad y el número de productos derivados. Se analizan las cadenas de valor global para conocer su gravitación y comprender mejor el sector del azúcar y el alcohol. Se muestra que su cadena de valor está bajo el control nacional, algo infrecuente en otras cadenas de las que el país forma parte. Finalmente, se destacan las innovaciones más recientes en el sector, que reflejan la preocupación por el incremento de la competitividad. 


\section{I}

\section{Introducción}

Pese a que la producción de alcohol y sobre todo de azúcar no son recientes en el Brasil, su importancia y difusión mundial han aumentado en el último período debido a que el alcohol combustible constituye un recurso renovable y sus emisiones de carbono a la atmósfera son prácticamente nulas. El surgimiento de los vehículos policarburantes (con motor flex-fuel) se tradujo en un incremento de la demanda nacional y - en menor escala- mundial y también dio un nuevo impulso al sector. ${ }^{1}$ Esto obedece a la búsqueda cada vez más intensa de fuentes de energía renovables y menos contaminantes para hacer frente a los problemas ambientales en todo el mundo y promover el crecimiento sostenible. Entre los problemas más graves se destaca el llamado efecto invernadero, que exige elevadas inversiones en investigación y desarrollo (ID) en este y otros sectores.

En este contexto se han registrado cambios en la política industrial y tecnológica del Brasil y de muchos otros países, en los que gradualmente comienza a mezclarse el etanol en la gasolina y se promueven nuevas normas ambientales y laborales para el sector azucarero, con el objetivo de incrementar las exportaciones y -de ser posible- mejorar sus repercusiones en el ambiente y los trabajadores.

El precio del petróleo, y por ende de la gasolina, influye directamente en la demanda de etanol en el mercado nacional y acrecienta aún más la importancia del sector. Además, se plantean temas estratégicos con respecto al potencial energético de la caña de azúcar, del que se utiliza solo un tercio debido a la falta de tecnología adecuada para la cogeneración y recolección de la paja en forma separada. Los avances tecnológicos en tal sentido pueden mitigar los problemas de escasez de energía en los períodos en que baja el nivel de los depósitos de agua brasileños (mayo-diciembre), precisamente la época más favorable para la cogeneración a partir de la quema de los

$\square$ Se agradecen los aportes de un colaborador anónimo. Los errores que puedan encontrarse son de responsabilidad de los autores.

${ }^{1}$ En varios países se han anunciado intenciones de iniciar o incrementar la adición de alcohol a la gasolina y el diésel. Entre ellos se encuentran los países de la Comunidad Europea, Angola, la Argentina, Australia, Benin, Estado Plurinacional de Bolivia, el Canadá, China, Colombia, los Estados Unidos, Filipinas, la India, el Japón, Mozambique, Nigeria, Sudáfrica, el Senegal, Tailandia, República Bolivariana de Venezuela y Zimbabwe (Negrão y Urban, 2005; Souza, 2006; Lima, 2007). residuos de la industria del azúcar y el alcohol del país (Piacente y Piacente, 2004; Vieira, 2003).

Muchos especialistas se preocupan por la posibilidad de que el cultivo de caña de azúcar sustituya a las plantaciones que antes proporcionaban alimentos a la población brasileña y mundial. Otros temen que la expansión de ese cultivo alcance a la selva amazónica, agudizando la deforestación y en consecuencia el impacto ambiental de esta industria.

Ante el crecimiento del sector azucarero y la necesidad de combinarlo con la sostenibilidad socioambiental de la agroindustria, surge la necesidad de nuevas tecnologías que garanticen, entre otras cosas, el aumento de la productividad, la eliminación de las quemas que anteceden a la cosecha, el adecuado descarte o utilización de los residuos productivos y una mayor eficiencia en la generación de energía. Las inversiones en investigación y desarrollo, ya sea por parte de centros de investigación o de empresas públicas o privadas, son imprescindibles para mantener el crecimiento de esta actividad.

El presente trabajo se divide en cinco secciones, incluida esta introducción. En la sección II se expone brevemente la trayectoria del sector del azúcar y el alcohol en el estado de São Paulo, principal productor del país, y las dificultades surgidas debido a su desregulación. También se detallan los principales productos de esa agroindustria y sus potenciales mercados; posteriormente se enumeran las ventajas comparativas del etanol brasileño con respecto al producido en los Estados Unidos y la Unión Europea.

En la sección III se presenta la cadena de valor del azúcar y el alcohol, para lo cual se explican brevemente las teorías de las cadenas de valor global y se analiza su aplicación a la industria de la caña de azúcar. En esa sección se enumeran también algunas de las dificultades para la globalización del sector.

En la sección IV se explica el estado actual de las innovaciones del sector del azúcar y el alcohol y la forma en que podrían contribuir a su desarrollo. Asimismo, se abordan algunos puntos considerados estratégicos para mantener la competitividad del sector a nivel internacional. En la quinta y última sección se presentan algunas consideraciones finales que ilustran los principales aspectos que han de mejorarse o a los que debe darse continuidad. 


\section{II}

\section{El estado de São Paulo y el sector del azúcar y el alcohol}

En el estado de São Paulo comenzó, después de 1929, una fase de grandes inversiones en la producción de caña de azúcar debido a la precaria situación del sector cafetalero, que representaba un elevado porcentaje de la economía paulista en esa época. En 1933, siguiendo la tendencia de diversificación productiva, el gobierno de Vargas creó el Instituto del Azúcar y del Alcohol (IAA), que entre otras funciones debería controlar la producción y molienda de la caña en el país.

El estado de São Paulo, que contaba con el mayor mercado interno y el apoyo del gobierno estadual (el más rico y mejor provisto del país) y de centros e institutos de investigación tecnológica (entre ellos el Instituto Agronómico de Campinas, IAC), se convirtió en el centro productivo brasileño más importante de ese sector. La prioridad que se asignó a la producción de caña de azúcar en ese estado se concretó con la implementación en 1975 del Programa Nacional del Alcohol (Proálcool), una política del gobierno federal.

Con dicho programa, el alcohol cobró importancia como fuente de energía renovable, característica a la que se da mucho más realce en la actualidad. Hasta 1975 la producción de alcohol combustible era pequeña y carecía de un mercado estable y con precios atractivos. Con el Proálcool, el gobierno federal pasó a garantizar ese mercado por medio de incentivos al uso de mezclas de alcohol anhidro en la gasolina y a la producción de vehículos que funcionaran con alcohol hidratado. Esto determinó varios cambios y el desarrollo del sector del azúcar y el alcohol. Los responsables de las industrias ligadas al sector - Dedini y Zanini- buscaron nuevas tecnologías de molienda relativas a la alimentación del primer tramo (con pico o estera metálica) y la preparación de la caña (mediante cilindros de presión o cuchillas desfibradoras que eliminan la necesidad del cilindro) en las escuelas francesa y cubana, que presentaban un mayor aprovechamiento que la brasileña, e hicieron que los centros de investigación nacionales, privados y públicos acrecentaran sus inversiones en el mejoramiento de las cepas (Mariotoni y Furtado, 2004).

En un período de 16 años, los descubrimientos realizados por esas empresas y centros de investigación se tradujeron en un incremento de la productividad agrícola de la industria azucarera de alrededor del $56,8 \%$ en el estado de São Paulo (de una media de 51 toneladas por hectárea antes del Proálcool (1975) a una media de 80 toneladas por hectárea en 1991). Esto contribuyó directamente a la reducción de los costos de producción agrícola, que corresponden a alrededor del $60 \%$ de los costos de la cadena productiva del sector. Además de aumentar la productividad, después de la implementación del Proálcool se amplió también la cantidad de caña procesada por los ingenios azucareros paulistas. De 1975 a 1985 esta se expandió en casi un 300\%: de 30,4 millones de toneladas a 121,7 millones de toneladas. La producción de alcohol y azúcar en el estado también creció de 362.300 metros cúbicos a 7,6 millones de metros cúbicos $(4.767 \%)$ y de 2,9 millones de toneladas a 3,4 millones de toneladas (18\%), respectivamente.

A pesar de esos excelentes resultados, en 1985 el Programa Nacional del Alcohol se volvió inviable desde el punto de vista financiero debido al bajo precio del petróleo (que alcanzó los 12 dólares el barril), el fin de los subsidios gubernamentales después de la desregulación y el aumento del precio internacional del azúcar (Michellon, Santos y Rodrigues, 2008). En la implementación del Proálcool pueden distinguirse tres períodos, desde su creación hasta 1990, a saber:

i) Expansión moderada (1975-1979), caracterizada por el incremento de la producción debido a elevados financiamientos para el montaje y la ampliación de las destilerías anexas a los ingenios de azúcar existentes, impulsados también por los incentivos al uso del alcohol como aditivo de la gasolina.

ii) Expansión acelerada (1980-1985), con un considerable engrosamiento de la producción de alcohol hidratado para uso directo en los vehículos y el consiguiente aumento de la producción de caña de azúcar en el Brasil (de 91,5 millones de toneladas en 1975-1976 a 225 millones de toneladas en 19851986).

iii) Desaceleración y crisis (1986-1990), cuando el alcohol pierde los subsidios otorgados hasta entonces por el Estado y se debilita ante la contracción de los precios del petróleo, que derivó en una menor 
proporción de vehículos a alcohol. Cabe recordar que el año 1990 marcó un cambio radical en la participación y forma de actuación del Estado en el Brasil, con el breve gobierno de Collor (19901992) interrumpido por un juicio político. Durante ese gobierno se promovió una acentuada apertura de la economía brasileña, se inició un proceso de privatización que duró hasta la década de 2000 y se retiró al Estado de una serie de sectores, incluido el del azúcar y el alcohol, al cerrarse el mencionado IAA fundado por Vargas en 1933.

\section{Desregulación del sector del azúcar y el alcohol y sus efectos económicos}

En 1990, el sector del azúcar y el alcohol sufrió una marcada desregulación. Fue uno de los sectores más afectados por los cambios en el ambiente institucional del país, que condujeron a la rearticulación de sus agentes sin la participación del Estado. Con el término de las intervenciones estatales, los agentes económicos adoptaron diferentes estrategias, caracterizadas por nuevas estructuras competitivas, fusiones y un acentuado proceso de migración de capitales a las regiones de "frontera de la caña de azúcar", perdiéndose la relativa equidad garantizada por el IAA en la distribución de la producción y en las garantías de oferta y precios (Vian y Belik, 2003).

Los ingenios en los que se dejó de invertir o buscar nuevas tecnologías de producción sufrieron lo que Schumpeter (1942) denomina proceso de destrucción creadora. Ese proceso conduce a que con el tiempo se establezca una organización autónoma de la economía industrial, que determina que las tecnologías, empresas y sectores obsoletos abandonen el mercado y sean sustituidos por otros más innovadores. Esto demuestra - sobre todo a largo plazo, cuando el proceso se vuelve inexorable- la importancia de la inversión en innovación para mantener o acrecentar la competitividad de las empresas en una economía capitalista (Nelson y Winter, 1974, 1977 y 1982).

Los cambios en los todos los ramos del sector del azúcar y el alcohol indujeron a los directores de las unidades agroindustriales a procurar, entre otras cosas, mayor flexibilidad de productos y procesos, mayor productividad mediante un mejor aprovechamiento de los insumos y continuidad en el mejoramiento de las cepas más productivas en términos de concentración de sacarosa (también, en este caso, con la ayuda continua de centros de investigación públicos y privados). En consecuencia, los responsables de la agroindustria buscaban los elementos que según Schumpeter (1942) garantizarían la supervivencia y las fuentes de mayores ganancias para las empresas insertadas en un mercado competitivo, es decir, la innovación y el desarrollo tecnológico. Esto difiere de la práctica generalizada hasta los años noventa, cuando los cambios más importantes en el régimen tecnológico del sector se orientaban a la racionalización de los costos de producción.

De acuerdo con Dosi (1988), esa búsqueda de nuevos productos y procesos no solo obedece a la capacitación y a los estímulos generados internamente en las empresas, sino también a causas externas como el estado de la ciencia en los diversos sectores, el acceso a recursos de ciencia y tecnología externos (centros de investigación públicos y universidades, entre otros), la facilidad de divulgación y comunicación del conocimiento, la calificación de la mano de obra, las condiciones del mercado y de protección (patentes), entre otras. Possas (2003) afirma que la interacción, la capacitación y el aprendizaje entre proveedores y colaboradores a lo largo de la cadena productiva pueden ser una importante fuente de innovaciones incrementales, difusión de nuevas tecnologías y apropiación de las ganancias derivadas del proceso innovador. Esto incrementa aún más la importancia de los proveedores y los centros de investigación públicos y privados, no solo en el sector del azúcar y el alcohol, sino también en los demás segmentos de la economía.

Los avances tecnológicos y productivos engrosaron considerablemente la rentabilidad económica de la agroindustria con respecto al período anterior a la desregulación. El descubrimiento de nuevos derivados (ácido acético, láctico y cítrico, plásticos biodegradables, papeles y fármacos, entre otros) surgió con la diferenciación e intensificación de las actividades de investigación y desarrollo realizadas por el centro de investigación de la Cooperativa de Produtores de Cana de Açúcar, Açúcar e Álcool do Estado de São Paulo (COPERSUCAR) y universidades públicas ligadas al sector (Assumpção, 2004; Coutinho, 1995). Además de esos nuevos subproductos obtenidos mediante la diversificación y las inversiones en investigación y desarrollo, la agroindustria de la caña de azúcar registró otras innovaciones, entre ellas, la producción de azúcares más finos para uso en alimentos dietéticos, bagazo de caña para la fabricación de forrajes y generación de energía, derivados químicos para uso cosmético y un nuevo subproducto, la energía eléctrica, capaz de ampliar aún más las posibilidades de ingresos en el proceso productivo de los ingenios (Fronzaglia y Martins, 2006; Baccarin y Castilho, 2002; Jank, 2008). 
Además de garantizar la permanencia de las empresas en el mercado al incrementar su competitividad, las inversiones en investigación y desarrollo pueden abrir nuevas oportunidades de negocios. Esto es posible cuando la empresa logra diversificar su producción, ingresando a nuevos mercados y volviéndose menos vulnerable a las crisis sectoriales (Penrose, 1959). De acuerdo con Penrose (1959), una empresa diversifica cuando, sin abandonar completamente sus antiguas líneas de productos, inicia la fabricación de otros productos, incluso productos intermedios, suficientemente diferentes de aquellos que ya fabricaba y cuya producción supone procesos de distribución, producción y de otro tipo también diferentes. El alcohol y sus derivados, la energía eléctrica y los azúcares dietéticos, entre otros, son algunos ejemplos de ese concepto de diversificación aplicado a la industria azucarera.

Algunos avances tecnológicos de la agroindustria analizada se fundan en una mayor reutilización de los residuos productivos en varias etapas de la producción. Los siguientes constituyen algunos ejemplos: i) la vinaza, un residuo de la producción de alcohol y azúcar utilizado en la irrigación de la tierra donde se plantará una nueva zafra; ii) el bagazo de caña, al que se da mucho uso en la cogeneración de energía eléctrica y, en menor escala, en la producción de forrajes, y iii) la paja, que no se aprovechó hasta la década de 1990, cuando comenzó a utilizarse para proteger el suelo después de la recolección de la caña (desde 2006 se analiza también la viabilidad de su uso en la cogeneración y la producción de alcohol mediante hidrólisis ácida o enzimática).

De acuerdo con Pavitt (1984, citado en Dosi, 1988 pág. 5), existen cuatro modos básicos para invertir en investigación y desarrollo, a saber: “i) proceso de búsqueda formalizado y económicamente dispendioso, cuyos costos son asumidos completamente por las empresas innovadoras; ii) procesos informales de difusión de información y capacitación tecnológica (por ejemplo, mediante publicaciones, asociaciones técnicas, procesos de aprendizaje mediante la observación, transferencia de personal); iii) formas particulares de externalidades en cada empresa, relacionadas con el concepto del aprendizaje práctico, y iv) adopción de innovaciones desarrolladas por otras industrias e incorporadas en el equipo de capital y en los insumos intermedios". En el sector estudiado se aplican sobre todo los dos últimos.

Entre los cambios e innovaciones y diversificaciones por las que pasó la agroindustria azucarera de 1975 a 1995 se encuentran varios ejemplos del proceso conocido como cambio o solución de paradigmas, que incluyen la creación de máquinas cosechadoras que evitan las quemas, el uso de la vinaza como fertilizante y el descubrimiento de nuevas variedades de caña de azúcar, entre otros.

\section{Principales productos de la industria azucarera}

\section{a) Etanol}

El Brasil es uno de los mayores productores de etanol del mundo con 17.500 millones de litros en 2006 (cerca del $34 \%$ de la producción mundial de 51.000 millones de litros de etanol ese año), y ocupa el segundo lugar después de los Estados Unidos, que produce 18.500 millones de litros, equivalentes al $36 \%$ de la producción mundial. Sin embargo, el etanol brasileño presenta ventajas con respecto al estadounidense en competitividad y precio debido a la diferencia energética de la materia prima utilizada y a las tecnologías aplicadas en ambos países. Por ese motivo, y también porque su demanda interna es menor, el Brasil es el mayor exportador de etanol del mundo. Los principales destinos de sus exportaciones son: la Unión Europea (29,3\%), los Estados Unidos (25\%), el Japón (10,3\%) y Jamaica (8,3\%) (FIESP, 2008; Neves y Conejero, 2007). Si bien la participación del Brasil en el mercado mundial de etanol es grande, se trata de un mercado todavía en desarrollo que ofrece muchas posibilidades hasta su consolidación. En 2005, el Brasil exportó cerca de 2.500 millones de litros de etanol, cantidad que superaba a las exportaciones de todos los otros países juntos (FIESP, 2008). De acuerdo con Souza (2006), el Brasil no exporta más alcohol combustible solo debido a los límites actuales para la producción nacional, incluso aunque esta ocupe el segundo lugar a nivel mundial. En el cuadro 1 y el gráfico 1 se detallan las exportaciones de los principales países del sector en 2006.

CUADRO 1

Exportación mundial de etanol, 2006

(En miles de millones de litros)

\begin{tabular}{lcc}
\hline País & Total & (Porcentaje del total) \\
\hline Brasil & 3,40 & $(64,8 \%)$ \\
Costa Rica y Jamaica & 0,30 & $(5,7 \%)$ \\
Sudáfrica & 0,20 & $(3,8 \%)$ \\
Estados Unidos & 0,20 & $(3,8 \%)$ \\
Arabia Saudita & 0,15 & $(2,9 \%)$ \\
China & 0,15 & $(2,9 \%)$ \\
Unión Europea & 0,10 & $(1,9 \%)$ \\
Otros & 0,75 & $(14,3 \%)$ \\
& & $(100,0 \%)$ \\
\hline
\end{tabular}

Fuente: Instituto de Estudios de Comercio y Negociaciones Internacionales (ICONE). 


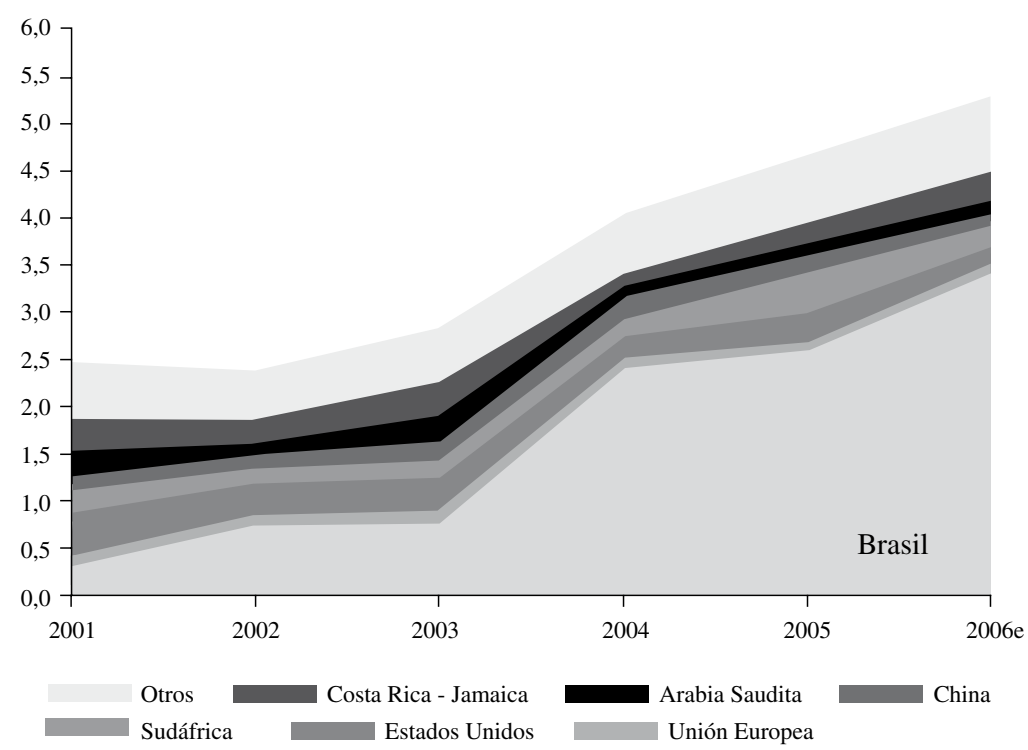

Fuente: Instituto de Estudios de Comercio y Negociaciones Internacionales (ICONE).

Nota: e = estimativa (los datos correspondientes al Brasil y los Estados Unidos fueron actualizados, los datos relativos a Sudáfrica se proyectaron sobre la base de datos preliminares de 2006, los datos de las exportaciones de otros países se proyectaron sobre la base de datos de años anteriores). En el caso de la Unión Europea, solo se tuvo en cuenta el comercio fuera del bloque.

Entre las principales causas del crecimiento del mercado del etanol se cuentan la ampliación de la flota de vehículos policarburantes, que en la actualidad se limita sobre todo al mercado nacional (y corresponde al $81 \%$ de las ventas de autos nuevos en 2007 , de acuerdo con la Asociación Nacional de Fabricantes de Vehículos Automotores, ANFAVEA), y el incremento o el inicio, dependiendo del país, de la política de mezcla o adición de alcohol a la gasolina en el mercado internacional (Toneto Jr., 2007). Además de contribuir a la expansión del consumo de etanol en el mercado interno, el surgimiento de vehículos con motores policarburantes creó una nueva relación entre este y la gasolina. Debido a que esos productos pasaron a ser sustitutos perfectos se estableció una pronunciada correlación entre sus precios y demandas.

Además de su marcada relación con la gasolina, el etanol compite con el azúcar en las decisiones de producción, pues esta aumenta o disminuye dependiendo de sus respectivos valores de mercado. Con la quiebra de la producción de azúcar en la India, por ejemplo, el precio de ese producto básico se disparó en el mercado internacional y esto derivó en que en muchos ingenios se modificaran las proporciones de producción para engrosar la oferta de azúcar.

Otro factor importante para el crecimiento de la demanda de alcohol proviene de su posible uso para la generación de nuevos subproductos en el ramo de la química. Eso sería posible mediante la transformación de los ingenios en biorrefinerías, es decir, complejos de equipos, instalaciones y procesos para convertir la biomasa en biocombustibles, productos químicos (alcohol etílico, butanol, acetona, entre otros) y energía eléctrica (cogeneración) (Bastos, 2007). A diferencia del azúcar, que ya posee un mercado consolidado, el comercio del etanol todavía es objeto de algunas barreras, a saber: i) proteccionismo; ii) falta de confianza en el mantenimiento de la oferta y en la calidad y procedencia del producto; iii) falta de estandarización; iv) insuficiencia de canales de distribución para llegar a todos los mercados del mundo.

La transformación del etanol en un producto básico global reduciría en gran medida el impacto de estas barreras y favorecería su comercialización. La estandarización es un presupuesto fundamental de todo producto básico y supone la divulgación y fiscalización de los datos respecto 
de la materia prima utilizada, la forma de producción y el respeto de las leyes ambientales, laborales y de calidad. Si bien el gobierno brasileño y diversas entidades sectoriales y ambientales han procurado la estandarización del etanol y los datos que la acompañan (Negrão y Urban, 2005), una parte de ese proceso depende de acuerdos internacionales que han de firmarse con otros productores y demandantes de etanol. Al tratarse de un proceso en curso, todavía no es posible prever sus resultados. Se entiende por producto básico cualquier producto, sobre todo agrícola o mineral, ampliamente negociado en el mercado internacional por importadores y exportadores. Para la negociación de estos productos existen bolsas de valores específicas; en el caso brasileño, la Bolsa de Mercaderías y Futuros (BM\&F).

\section{b) Azúcar}

La demanda mundial de azúcar se relaciona directamente con el ingreso y el crecimiento de la población. En función del incremento del ingreso nacional e internacional, seguido de la ampliación del mercado mundial, se espera un aumento en el consumo nacional e internacional del azúcar industrial, utilizado principalmente en las industrias de refrigerantes, chocolates, alimentos y helados (Vieira, 2006).

También existen expectativas de que crezca la demanda de azúcar a raíz de una mayor participación de los países asiáticos en el mercado mundial, en particular China, que todavía presenta un reducido consumo de azúcar per cápita ( 7 kilos por persona/año, en comparación con 58 kilos en el Brasil, 18 kilos en la India, 34 kilos en los Estados Unidos y 38 kilos en la Unión Europea). Asimismo, la Organización Mundial del Comercio (OMC) se ha mostrado contraria a la exportación de azúcar subsidiada por los países europeos, debido a los avances de países como el Brasil y Australia en dicho organismo. Esto garantizaría la apertura de nuevos mercados para el azúcar brasileño (Neves y Conejero, 2007; Toneto Jr., 2007; Vieira, 2006).

El Brasil es el mayor productor de azúcar del mundo (32,3 millones de toneladas, equivalentes al $20 \%$ de la producción mundial) y sus principales competidores directos son la Unión Europea (12\%), la India (10\%) y China (9\%). Según datos del Departamento de Agricultura de los Estados Unidos, el Brasil, a pesar de ser el primer país desde el punto de vista de la producción, presentó la menor tasa de crecimiento acumulado de la producción entre 2004 y 2008 (16,5\%), en comparación con la India $(103,18 \%)$ y China $(31,79 \%)$. El bajo precio del azúcar en el comercio mundial y la creciente demanda interna de etanol podrían explicar esa disminución.
Pese a que el consumo per cápita de azúcar es elevado en el Brasil, este país exporta más del $60 \%$ de la producción. Esa cifra equivalió a más de 20 millones de toneladas en 2008, en comparación con los 5,5 millones de toneladas exportadas por Tailandia y los 4 millones de toneladas exportadas por Australia, sus principales competidores en exportación (Ministério da Agricultura, Pecuária e Abastecimento, 2009). Con el objeto de exportar parte de la producción, en la Unión Europea se recurre a elevados subsidios, a pesar de las fuertes barreras que se aplican al ingreso del etanol brasileño en el mercado del bloque (Mariotoni y Furtado, 2004).

\section{c) Energía eléctrica}

La autosuficiencia en la producción de energía eléctrica en los ingenios y la búsqueda de generación de excedente mediante la cogeneración abrieron paso al surgimiento de un nuevo mercado y un nuevo producto en el sector del azúcar y el alcohol. En los ingenios paulistas, por ejemplo, por cada tonelada de caña se produce una media de 140 kilos de bagazo (materia seca), cuyo $90 \%$ se utiliza para la producción de energía en el ingenio. Por cada tonelada de caña se producen también 140 kilos de paja, que representan un potencial sin explotar, pues si bien en la actualidad se queman o dejan en el campo, podrían utilizarse para elevar la generación de energía o, en el futuro, como se verá más adelante, para acrecentar la producción de etanol (mediante hidrólisis) (Vieira, 2006).

La creciente demanda de energía eléctrica en el Brasil, debido al desarrollo económico y la búsqueda de fuentes de energía renovables y limpias, otorgó más importancia a la cogeneración en la matriz energética brasileña. Un hecho relevante con respecto a esa nueva fuente de energía, que forma parte de la matriz energética del país desde fines de los años setenta, es la coincidencia del período de generación con el de escasez de energía hidroeléctrica (mayo-diciembre) debido a la reducción de los índices pluviométricos y al vaciado de los depósitos de agua. No obstante, la cogeneración debe todavía superar algunas barreras internas, incluidas entre otras: i) la necesidad de venta durante todo el año; ii) la integración eficiente con las líneas de transmisión para reducir las pérdidas por disipación; iii) el precio, y iv) el formato de la licitación (Piacente y Piacente, 2004; Vieira, 2006; Toneto Jr, 2007).

De acuerdo con Souza (1999), la inversión media por kilovatio instalado en la agroindustria para la cogeneración varía entre 300 dólares y 1.500 dólares. Rodrigues (2001, citado en Piacente y Piacente, 2004) afirma que, además de requerir de 8 a 12 años, la construcción 
de una planta hidroeléctrica de gran tamaño presenta un costo de alrededor de 2.000 dólares por kilovatio, mientras que una central nuclear tarda el mismo tiempo en construirse y la inversión por kilovatio no baja de 4.000 dólares. En consecuencia, se puede afirmar que invertir en el incremento de la generación de energía por los ingenios es mucho más viable económicamente en el corto plazo, además de que no depende de la importación de insumos o equipos, como en el caso de la energía nuclear.

\section{El Brasil, los Estados Unidos y la Unión Europea: ventajas individuales en la producción de etanol}

El etanol se fabrica también en otros países, además del Brasil, los Estados Unidos y la Unión Europea. No obstante, entre los dos países y el bloque mencionados, solo en el Brasil se hace exclusivamente de caña de azúcar como materia prima. Mientras que en los Estados Unidos se produce etanol a partir del maíz, lo que ha causado problemas en el suministro de ese alimento en el mercado interno y externo, en la Unión Europea se utiliza sobre todo la remolacha, con la que también se produce el azúcar.

Pese a que el Brasil cedió en 2006 el puesto de mayor productor mundial de etanol en favor de los Estados Unidos (como se observa en el gráfico 2), presenta grandes ventajas comparativas con respecto a la materia prima utilizada, el costo de producción, la productividad, el potencial energético y la disponibilidad de tierras para expandir la producción. Mientras que el costo de la producción de un litro de etanol de caña de azúcar era de alrededor de 0,20 dólares en el Brasil en 2005, el litro de etanol de maíz de los Estados Unidos costaba 0,45 dólares y el de la Unión Europea 0,65 dólares (FIESP, 2008).

De acuerdo con Rodrigues (2008), de mantenerse o reducirse el costo de producción del etanol brasileño, este podría permanecer competitivo con respecto a la gasolina, siempre que el precio del barril de petróleo no sea inferior a los 40 dólares. ${ }^{2} \mathrm{El}$ Brasil también presenta ventajas desde el punto de vista de la productividad. En 2005 esta era de alrededor de 7.000 litros por hectárea, muy superior a la de los Estados Unidos, de 3.000 litros por hectárea, y a la de la Unión Europea, de 5.500 litros por hectárea (FIESP, 2008; BNDES, 2008).

Con respecto al balance energético de las materias primas utilizadas en esos tres países en la producción de etanol, al comparar la energía consumida en todas las

\footnotetext{
2 Roberto Rodrigues, ex ministro de agricultura, Coordinador del Centro de Agronegocio de la Fundación Getulio Vargas, Presidente del Consejo Superior de Agronegocios de la Federación de Industrias del Estado de Sao Paulo (FIESP) y copresidente de la Comisión Interamericana de Etanol.
} GRÁFICO 2

Producción mundial de etanol (En porcentajes)

Producción total: 51.100 millones de litros

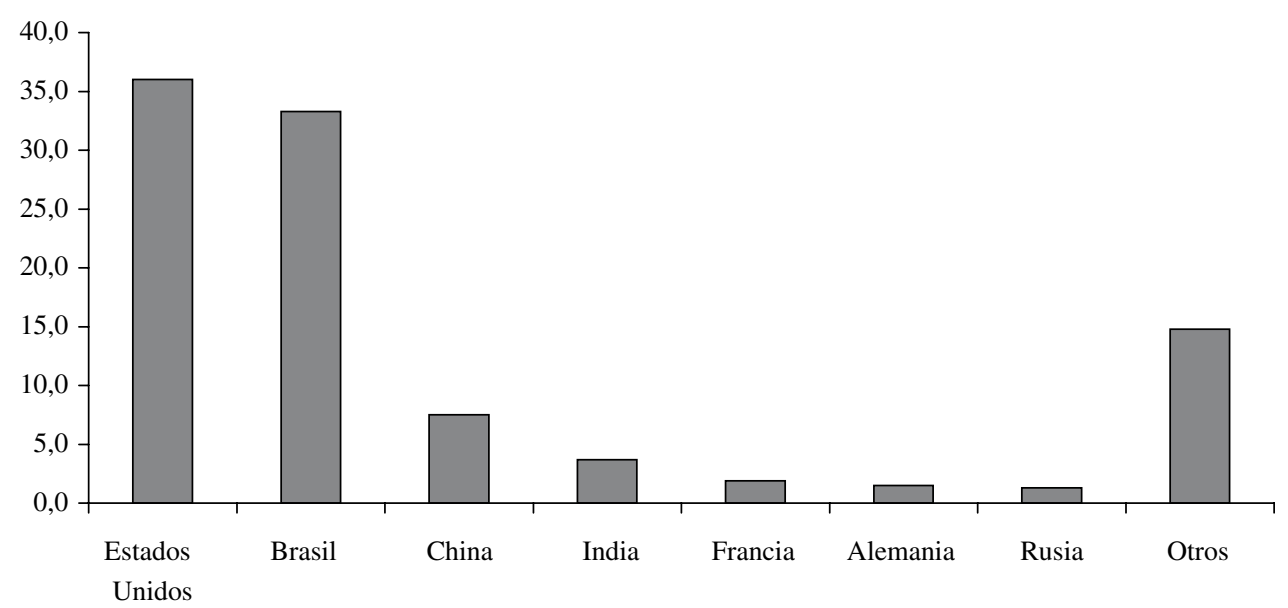

Fuente: elaboración propia sobre la base de datos de la Federación de Industrias del Estado de São Paulo (FIESP), Agronegócio brasileiro, São Paulo, 2008. 
etapas de fabricación (plantación, recolección, transporte y molienda, entre otras) con la energía renovable generada, se observa que el rendimiento de la caña de azúcar es casi ocho veces mayor que el del maíz. Con el etanol de la caña de azúcar se liberan alrededor de 8,9 unidades de energía por cada unidad de energía consumida, mientras que esa proporción es de 1 a 1,5 en el caso del etanol de maíz y de aproximadamente 1 a 2 en el caso del etanol de remolacha (Macedo, 2007).

La capacidad de generación de energía de la caña de azúcar no se limita solo al etanol, que representa apenas un tercio de la energía contenida en la caña. Como ya se mencionó, la cogeneración de energía es otra importante fuente de energía renovable que los residuos de la caña de azúcar pueden proporcionar. Eso explica el diferencial de potencial energético entre las materias primas examinadas.

Al no utilizar una materia prima alimenticia - como en el caso de los Estados Unidos- y no ocupar el espacio de las plantaciones de alimentos en virtud de las grandes áreas cultivables disponibles en el país, el sector del azúcar y el alcohol brasileño, al contrario de lo que afirman algunos especialistas, no tiene ninguna relación directa con el aumento de los precios de los alimentos. Tampoco se debe temer el avance del cultivo de caña de azúcar hasta la Amazonia, visto que la elevada humedad en ese territorio durante todo el año reduciría la productividad de las variedades de caña utilizadas y conocidas a nivel nacional. Por el contrario, si bien el incremento del consumo de maíz derivado de los mejores niveles de ingresos, sobre todo en las economías asiáticas y de Europa oriental, es uno de los principales factores de la reciente crisis entre la oferta y la demanda de ese producto, el aumento de la producción de etanol en los Estados Unidos también podría ser parcialmente responsable de la crisis de alimentos, puesto que el maíz es uno de los principales alimentos del mundo y sobre todo de América (IPEA, 2008).

Cabe destacar que, en virtud de las proporciones del territorio brasileño, todavía existe un amplio margen para el crecimiento del cultivo de caña de azúcar, incluso sin avanzar sobre la Amazonia Legal. En el gráfico 3 se ilustra la distribución de los 851 millones de hectáreas de área libre existentes en el Brasil.
GRÁFICO 3

\section{División del territorio brasileño}

(En millones de hectáreas)

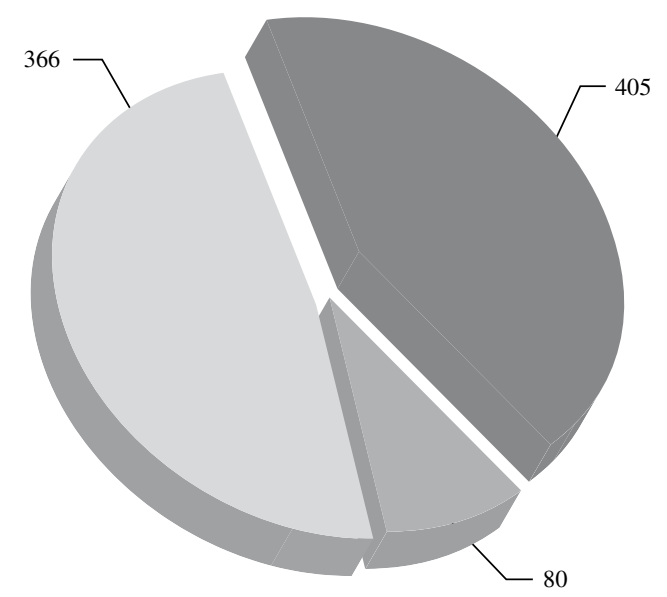

Áreas protegidas y Amazonia Legal

Ciudades/Carreteras/Ríos/Lagos

Áreas de producción/agropecuaria

Fuente: elaboración propia sobre la base de datos de la Secretaria de Produção e Agroenergia (SPAE) del Ministério da Agricultura, Pecuária e Abastecimento.

De los 366 millones de hectáreas (43\%) de suelo cultivable, la caña de azúcar ocupa solo 6,2 millones de hectáreas $(1,69 \%)$, mientras que las pasturas y áreas fértiles y vírgenes de frontera agrícola abarcan 300 millones de hectáreas $(81,97 \%)$ (Salibe, 2008).

Habida cuenta de que la producción pecuaria brasileña es muy amplia y, con algunas inversiones, puede mantenerse en un espacio territorial menor y en las grandes áreas fértiles y vírgenes que posee el país, existen grandes posibilidades para que el sector del azúcar y el alcohol continúe creciendo sin afectar a la producción de otros productos agrícolas. Además, gracias a las inversiones en nuevas tecnologías (por ejemplo, etanol de celulosa), las perspectivas de un acentuamiento de la productividad del sector podrían garantizar una producción mayor sin necesidad de acrecentar la cantidad de caña plantada. 


\section{III}

\section{Cadena de valor del sector del azúcar y el alcohol}

De acuerdo con Kaplinsky (2000, citado en Stamer, Maggi y Seibel, 2001, pág. 9), una cadena de valor puede entenderse como "un conjunto completo de actividades requeridas para viabilizar determinado producto o servicio, desde la concepción y la producción hasta la entrega al consumidor final y su disposición después del uso". De ese modo, toda la producción e incluso las actividades de investigación forman parte de la cadena de valor.

A partir del concepto de cadenas de valor, Sturgeon (1997) analizó un nuevo tipo de organización industrial cuya característica principal es la separación de las funciones corporativas en innovadoras y productivas. El abandono de las funciones productivas por algunas empresas y sectores puede explicarse en parte mediante el concepto de cadenas de valor global. Cuando las cadenas están bajo el dominio de grandes compradores o grandes empresas es frecuente la subcontratación de empresas en países menos desarrollados —donde la producción es más barata— para la realización de productos estandarizados con la marca de dichos compradores. Si las cadenas están bajo el dominio de los productores, estos controlarán las etapas más importantes, incluidas —en algunos casos- las operaciones de comercialización (marca, publicidad y formas de distribución, entre otros aspectos).

Mediante las cadenas de valor global es posible analizar la forma en que varias actividades están vinculadas, incluso en una economía globalizada. Esta mayor integración de la producción y del comercio entre empresas de diferentes países se vio facilitada por el desarrollo de nuevas tecnologías de comunicación y transporte (Gereffi y Korzeniewicz, 1994). Humphrey (2006) hace hincapié en el comercio mundial de productos agrícolas, que comprende a la agroindustria azucarera, y expone tres desafíos principales a que deben hacer frente las empresas y sectores que desean globalizarse:

i) Producir conforme con las exigencias mundiales, dada la importancia cada vez mayor de los estándares relativos a los productos agrícolas; satisfacer las exigencias de seguridad de los alimentos de los países importadores proporcionando información sobre el modo de cultivo, recolección, procesamiento y transporte.

ii) Satisfacer las exigencias de los compradores globales en velocidad y confiabilidad de la entrega, modificación por encargo de los productos con respecto al procesamiento y embalaje y garantías sobre la seguridad del producto.

iii) Agregar valor a los productos agrícolas de exportación, sobre todo en el caso de los países en desarrollo cuya pauta exportadora se compone principalmente de productos primarios.

La aplicación del esquema de las cadenas de valor global a un negocio agrícola permite analizar las causas y consecuencias de la coordinación vertical organizada e implementada en los diversos sectores del negocio. En primer lugar, se analiza el papel de las empresas subcontratadas y la posición de los productores en esas cadenas, ya sea subordinada o de comando. Posteriormente se teoriza sobre los factores determinantes de las diferentes formas de coordinación vertical. Por último, se examinan las consecuencias de la dinámica de la cadena de valor en las estructuras productivas de los países desarrollados y en desarrollo y en la distribución de ingresos entre empresas en las diferentes etapas de la cadena y en cada uno de esos lugares (Humphrey, 2006).

Las principales formas de coordinación de las relaciones entre agentes integrados en una cadena de valor son las siguientes:

i) Enlaces relacionales: mediante asociaciones estratégicas. La dependencia entre los participantes es mutua y está regulada por la reputación, la proximidad social y los lazos étnicos, entre otros aspectos.

ii) Enlaces prisioneros: los proveedores terminan por depender de los grandes compradores. Estas redes se caracterizan frecuentemente por un elevado grado de supervisión y control por parte de la empresa contratante.

iii) Enlaces modulares: las ganancias en los costos de los productos y servicios se obtienen sin necesidad de inversiones específicas a las transacciones. En este caso los proveedores fabrican productos y prestan servicios sometidos a las especificaciones de un comprador (Gereffi y Korzeniewicz, 1994; Sturgeon, 2006; Humphrey, 2006).

$\mathrm{El}$ análisis de los diferentes enlaces se basa en tres variables explicativas, a saber:

- complejidad de la información que debe transferirse entre los actores de la cadena para que la transacción tenga éxito; 
- medida en que la información puede confiarse y en consecuencia transferirse en forma eficiente y sin inversiones específicas, y

- nivel de competencia de los proveedores con respecto a las exigencias que se les plantean (Humphrey, 2006). Los aspectos centrales de la cadena de valor del sector azucarero son su control por empresas nacionales brasileñas - aunque con el ingreso de algunas empresas transnacionales importantes al país en el último período- - y la integración básicamente total de la cadena en el interior del país. En ese sentido, casi se podría hablar de una "cadena brasileña de valor".

Los responsables del sector analizado en este trabajo se muestran poco propensos a relacionarse con proveedores desconocidos y de potencial incierto. Sin embargo, se observa una marcada relación con las cooperativas, que muchas veces son responsables de las actividades de investigación y desarrollo del sector (por ejemplo, en el caso de la Cooperativa de Produtores de Cana de Açúcar, Açúcar e Álcool do Estado de São Paulo, Copersucar), con grandes empresas ya consolidadas en el mercado y con importantes centros de investigación y universidades, ya sean estaduales, federales o privadas, que también realizan actividades de investigación y desarrollo, como explican Nelson y Winter (1982) para el sector agrícola en general.

La cadena productiva de la agroindustria de la caña de azúcar sufrió profundos cambios tecnológicos en los últimos años, debido a su importancia para la economía y a la matriz energética del país (Ramos y Souza, 2003). La cadena productiva del azúcar y el alcohol se internacionalizó a partir de la segunda mitad de la década de 1990, con el objetivo de ampliar la capacidad productiva de azúcar debido a la influencia de las empresas transnacionales productoras de alimentos (Assumpção, 2004). Recientemente se registró una nueva etapa de internacionalización, esta vez a objeto de ampliar la capacidad productiva de etanol dada su creciente importancia ambiental y económica a nivel internacional.

El mayor problema de la cadena de valor global del etanol se refería al mercado y a las economías de escala, a causa de la poca demanda internacional hasta 2001-2002, cuando en algunos países creció el interés en la mezcla de etanol en la gasolina y aumentaron las exportaciones brasileñas (véase el cuadro 2). La medida en que algunos factores locales afectaban a la demanda y la producción también constituía un problema para la globalización del etanol, pues antes de las ingentes inversiones destinadas a ampliar la capacidad productiva brasileña (a partir de 20022003, con miras a un incremento de la exportación) la producción se dirigía casi exclusivamente a abastecer el mercado interno, que aún hoy gravita mayormente en las ventas del sector. La cadena productiva de la caña de azúcar en el Brasil está completamente estructurada. El país domina todo el proceso productivo y de distribución y posee las mejores tecnologías para la producción de alcohol y azúcar del mundo (véase el gráfico 4).

CUADRO 2

Demanda y oferta de etanol en el Brasil y en el mundo

(En miles de millones de litros)

\begin{tabular}{|c|c|c|c|}
\hline \multirow{2}{*}{ Países } & \multicolumn{3}{|c|}{ Demanda por país } \\
\hline & 2003 & 2005 & $2010^{\mathrm{a}}$ \\
\hline Brasil & 12,9 & 14,0 & 17,4 \\
\hline Estados Unidos & 10,6 & 13,3 & 18,9 \\
\hline Canadá & 0,4 & 0,8 & 1,5 \\
\hline Unión Europea & 1,5 & 4,9 & 12,9 \\
\hline Japón & 0,8 & 1,9 & 7,2 \\
\hline Otros & 1,5 & 1,5 & 2,3 \\
\hline Total & 27,7 & 36,4 & 60,2 \\
\hline \multicolumn{4}{|c|}{$\begin{array}{l}\text { Brasil } \\
\text { Oferta }\end{array}$} \\
\hline 2003 & \multicolumn{2}{|c|}{2005} & $2010^{\mathrm{a}}$ \\
\hline 12,5 & \multicolumn{2}{|c|}{15,8} & 26,0 \\
\hline \multicolumn{4}{|c|}{$\begin{array}{c}\text { Exportaciones } \\
\text { (Exportaciones/oferta, en porcentajes) }\end{array}$} \\
\hline 2003 & \multicolumn{2}{|c|}{2005} & $2010^{\mathrm{a}}$ \\
\hline $\begin{array}{c}0,7 \\
(5,6 \%)\end{array}$ & \multicolumn{2}{|c|}{$\begin{array}{c}2,6 \\
(16,5 \%)\end{array}$} & $\begin{array}{c}7,2 \\
(27,7 \%)\end{array}$ \\
\hline
\end{tabular}

Fuente: elaboración propia sobre la base de datos de la União da Indústria de Cana-de-Açúcar (ÚNICA) y Ministério da Agricultura, Pecuária e Abastecimento, Anuário estatístico da agroenergia, Brasilia, 2009.

a Valores estimados. 


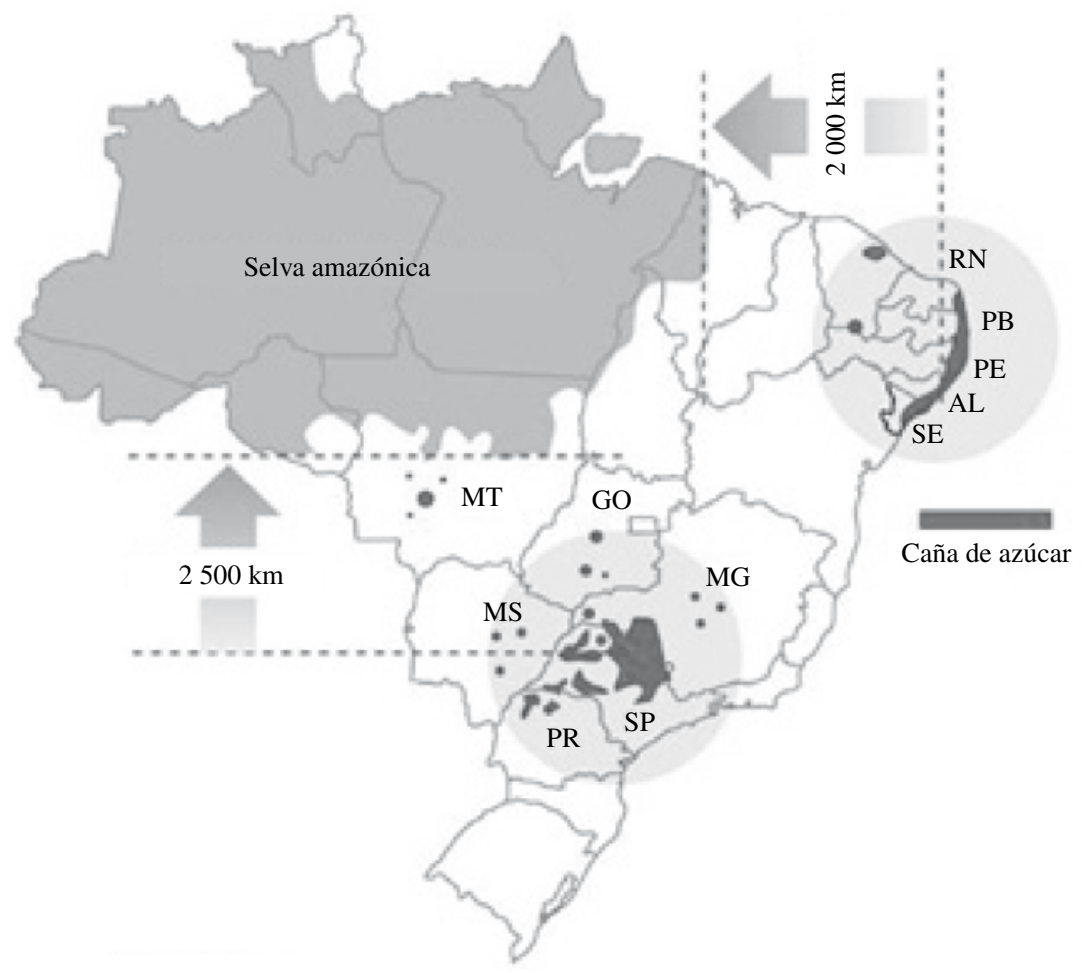

Fuente: União da Indústria de Cana-de-Açúcar (ÚNICA).

(Mapa): MT (Mato Grosso), Go (Goiás), MG (Minas Gerais), Ms (Mato Grosso do Sul), PR (Paraná), SP (São Paulo). (Círculo): RN (Rio Grande do Norte), PB (Paraíba), PE (Pernambuco), AL (Alagoas), se (Sergipe).

\section{IV}

\section{Estado actual de las innovaciones en el sector del azúcar y el alcohol}

La cadena productiva del azúcar y el alcohol se divide muchas veces en dos tipos de actividades: agrícola e industrial. En este artículo la cadena de valor del sector del azúcar y el alcohol se divide en cuatro etapas: i) agrícola; ii) eslabón entre el sector agrícola y el industrial; iii) industrial, y iv) comercial, como se ilustra en el gráfico 5. No se incluyeron los procesos de investigación tecnológica (investigación y desarrollo) y capacitación de profesionales por ser, en su mayoría, externos a los ingenios. A continuación se presentan las principales innovaciones en cada etapa de la cadena productiva en los últimos años.

\section{Actividad agrícola}

A pesar de su simplicidad, la cadena productiva de la fase agrícola es responsable directa del éxito del resto del proceso productivo y representa alrededor del $60 \%$ de los costos de toda la cadena del azúcar y el alcohol. El cultivo de caña de azúcar ha sido controlado mediante satélite por la Empresa Brasileña de Investigación Agropecuaria (EMBRAPA), en el marco de un proyecto para el que se creó una serie de rutinas y procedimientos propios para la detección, identificación, calificación y cartografía del cultivo. El uso de satélites ha contribuido 


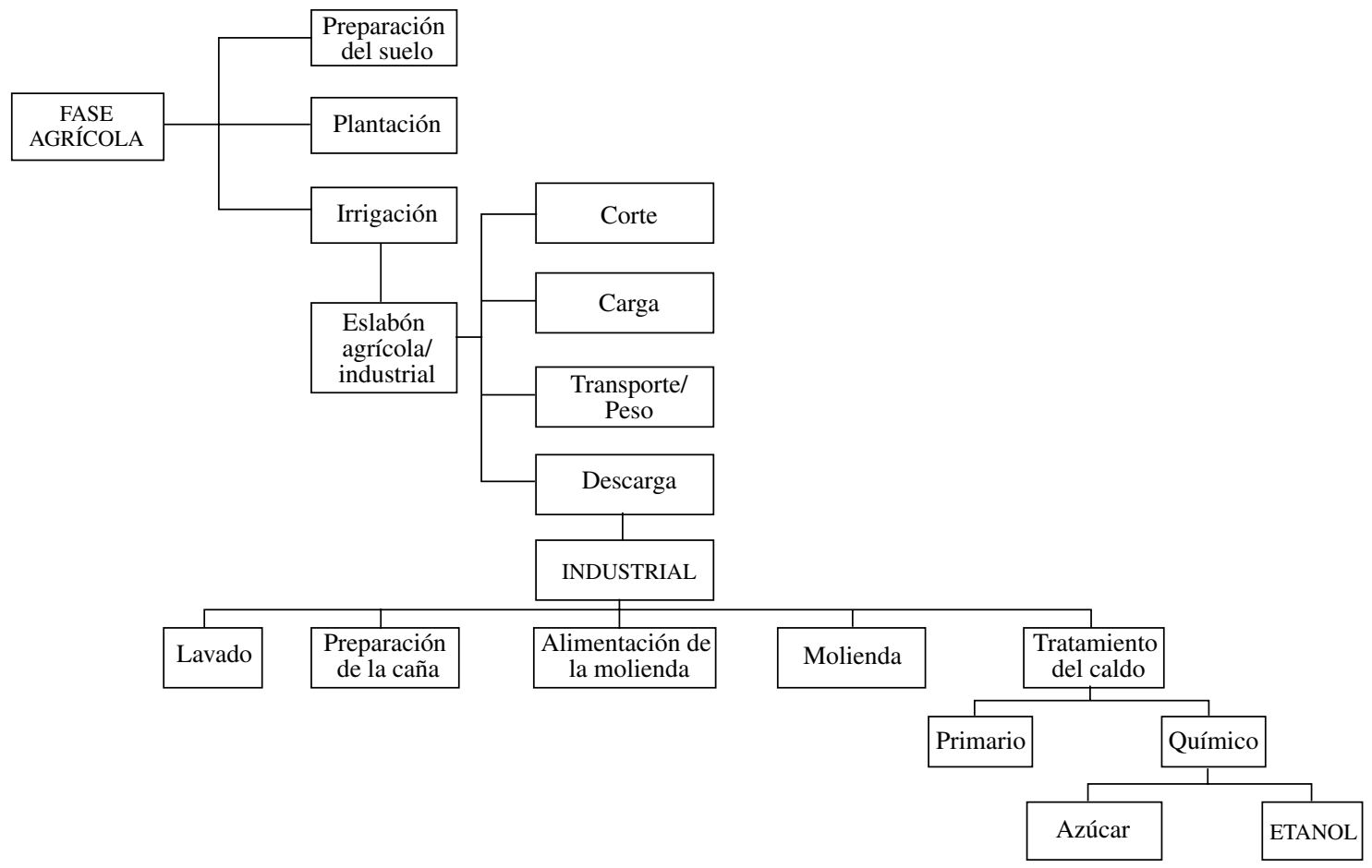

Fuente: elaboración propia sobre la base de datos de la União da Indústria de Cana-de-Açúcar (ÚNICA).

al desarrollo de una agricultura de precisión para la caña de azúcar. Este tipo de agricultura permite el trazado de mapas detallados de las condiciones del suelo y de la propiedad rural, que a su vez permite el análisis de la viabilidad de la plantación y recolección mecanizadas. Además, garantiza el seguimiento de la productividad del suelo, que facilita el conocimiento de sus necesidades nutricionales (Abarca, 1999).

Gran parte de los nutrientes necesarios para la preparación del terreno destinado a la siembra provienen de los residuos de esta agroindustria, que se utilizan en la fertilización del suelo y garantizan un ahorro del 30\% en ese proceso. El uso de este fertilizante orgánico y el cultivo de variedades mejoradas de caña de azúcar culminaron en un incremento de alrededor del 15\% de la productividad del terreno. La torta de filtro, un residuo formado por la mezcla de bagazo molido y lodo de la decantación, es un compuesto orgánico $(85 \%$ de su composición) rico en calcio, nitrógeno y potasio. Su uso cada vez mayor como sustituto de insumos tradicionales a base de potasio se observa principalmente en la operación de plantación. La vinaza, otro residuo del sector, se utiliza en la fertirrigación del cultivo de la caña de azúcar. Derivada de la destilación y fermentación de la caña de azúcar en el proceso de fabricación del alcohol, la vinaza es rica en materia orgánica y nutrientes minerales como potasio $(\mathrm{K})$, calcio $(\mathrm{Ca})$ y azufre $(\mathrm{S})$, y su $\mathrm{pH}$ varía entre 3,7 y 5,0 (Piacente y Piacente, 2004).

La genética de la caña de azúcar es una de las áreas del sector en que se registraron mayores avances. En la actualidad es posible elegir el mejor tipo de caña que ha de plantarse en determinado suelo, comparando la resistencia a las plagas, la productividad, la concentración de sacarosa, la inclinación y el tamaño, entre otros parámetros. Al inicio del Proálcool existían en el Brasil cinco o seis variedades comerciales de caña de azúcar. En la actualidad existen más de 500 variedades, que forman un patrimonio genético considerable y que tiende a aumentar. El incremento del número de variedades comerciales, condicionado al mejoramiento genético, es también responsable directo del acrecentamiento de la productividad de la caña de azúcar, que pasó de 47 toneladas por hectárea en los años setenta a 82 toneladas por hectárea en 2005 (FAPESP, 2006). 
Como ejemplo de la evolución genética del sector, cabe destacar dos estudios nacionales totalmente innovadores. El primero, realizado por investigadores de la Escola Superior de Agricultura "Luiz de Queiroz” (ESALQ)/ Universidad de São Paulo, se refiere a la creación, mediante la modificación genética, de un tipo de caña que libera proteínas con actividad insecticida cuando sufre el ataque de la Diatraea saccharalis, un insecto que penetra en el interior de la planta y cava galerías internas, causando grandes daños a los productores. De no ocurrir un ataque de este tipo, la planta continúa siendo "convencional" y su fenotipo no sufre ninguna modificación. En el marco del segundo estudio, realizado por la Empresa Brasileña de Investigación Agropecuaria (EMBRAPA Agrobiología), se logró descifrar la secuencia del código genético de la Gluconacetobacter Diazotrophicus, una de las bacterias responsables de la fijación biológica de nitrógeno en la caña de azúcar. Este descubrimiento permitirá incrementar el potencial de generación de nitrógeno por la bacteria, que en consecuencia reducirá la necesidad de fertilizantes a base de nitrógeno para el desarrollo de la plantación de caña, disminuyendo así el costo de producción (JornalCana, 2007; FAPESP, 2006).

La mayor demanda de azúcar y etanol, que impulsa la expansión del sector a nuevas áreas, acentúa aún más la importancia de la inversión en variedades genéticas de la caña de azúcar, en función de las diversas condiciones de suelos y climáticas. En atención a esa demanda se ha investigado y aprendido mucho en lo que se refiere al mejoramiento de la calidad de la caña.

Debido a que la composición natural de la caña incluye una gran concentración de agua, el principal desafío consiste en reducir esa proporción y acrecentar la de los azúcares, que garantizan una mayor productividad. Se han creado muchas variedades, que difieren en cuanto a la precocidad, el brote de la raíz, la concentración de sacarosa, la concentración de fibras y bagazo y el porte (que facilita o dificulta la recolección mecanizada), entre otros aspectos. Además de un mejor aprovechamiento de los azúcares para la producción de etanol y azúcar, la elección de la caña de azúcar adecuada para cada tipo de suelo y necesidad agroindustrial asegura una mayor eficiencia en la recolección — cuando se elige el porte específico-y en la generación de energía eléctrica dada su concentración de fibra.

\section{Eslabón entre el sector agrícola y el industrial}

Esta fase, que incluye el corte de la caña, el transporte, la descarga y el almacenamiento, es la que ha generado mayores controversias en el escenario nacional y sectorial.
En primer lugar, la mecanización de la cosecha se ha intensificado debido a las leyes ambientales destinadas a evitar las quemas, que sin embargo son esenciales para que pueda realizarse la recolección manual. Por otra parte, surge el problema de la mano de obra, pues la recolección manual se realiza en condiciones infrahumanas y por ese motivo es objeto de críticas nacionales e internacionales. De ese modo, la búsqueda de mayor eficiencia en la cosecha mecanizada tiene por objeto reducir las quemas y eliminar el trabajo manual en el campo. Esa es una de las necesidades que han de atenderse en el sector azucarero y que incluyen además el respeto de la legislación ambiental, laboral y social, la eliminación de las quemas, el mejoramiento de las condiciones de trabajo y, de ser posible, el mantenimiento de los puestos de trabajo de los trabajadores rurales. Ante esos desafíos, los responsables de la agroindustria deben, además de invertir en tecnologías para viabilizar y ampliar la recolección mecanizada, incentivar y ofrecer cursos de profesionalización y capacitación para que los antiguos jornaleros agrícolas puedan dirigir una máquina cosechadora computarizada, a fin de mantener su empleo actual y eliminar la necesidad de la quema para la recolección (Bragato y otros, 2008).

Si bien no es muy reciente, la recolección mecanizada ha sufrido diversas innovaciones con el objeto de hacer más eficientes las máquinas cosechadoras. Entre ellas se destacan las siguientes:

i) Reducción de la compactación del suelo y de la consiguiente pérdida de las raíces, mediante la utilización de máquinas más livianas o cuyas ruedas estén a la misma distancia que las hileras de las plantaciones de caña.

ii) Fabricación de máquinas que logren cosechar en terrenos con una pendiente superior al $12 \%$ y permitan incrementar la mecanización de la cosecha.

iii) Optimización del proceso de recolección de la caña con la paja, para el posterior uso de esta última en la industria como fuente de energía en la cogeneración o, incluso, en un futuro próximo, la generación adicional de alcohol (Manechini, Junior y Donzelli, 2005).

El sector de transporte de la caña de azúcar también ha desempeñado un papel importante en el proceso de modernización y de inversiones en investigación de la agroindustria. Los estudios relativos a esta fase se orientan al ahorro de combustible, la racionalización de la flota y el mantenimiento del flujo de caña para alimentar las moliendas. El corte, la carga y el transporte representan el $30 \%$ del costo de la producción de caña y 
solo el transporte equivale al $12 \%$ de esa cifra (Iannoni y Morabito, 2002).

Una de las principales metas de las inversiones e investigaciones en el sistema de transporte se refiere a la reducción del tiempo de inactividad y al ciclo de los camiones, es decir, al tiempo que transcurre desde el ingreso del camión en el ingenio a la descarga y el regreso al campo, la nueva carga en el campo y el regreso al ingenio una vez más. En otras palabras, se procura optimizar las operaciones que involucran a esos vehículos, cuyo tiempo de inactividad en las fases agrícola e industrial se traduce en altos costos para los ingenios. Para ello se han realizado grandes inversiones en logística y en la automatización del proceso de control (Iannoni y Morabito, 2002).

\section{Actividad industrial propiamente dicha}

En el período de 1975 a 1994 el área industrial registró avances tecnológicos que contribuyeron a acrecentar la capacidad de molienda en un $100 \%$, al aumento de la eficiencia del proceso de extracción del 93\% al 97\% y del proceso de fermentación del $80 \%$ al $91 \%$. En el mismo período también se logró reducir un $44 \%$ del consumo de vapor en la destilación (Abarca, 1999). Sin embargo, esas ganancias se lograron exclusivamente sobre la base de innovaciones incrementales, manteniéndose el mismo paradigma tecnológico. Esas innovaciones se refieren, por ejemplo, a la instalación de una serie de equipos periféricos y a la aplicación de nuevos procedimientos operativos en las moliendas y la extracción.

Con la aceleración de las innovaciones y modificaciones observadas en el sector, hubo una mayor demanda de tecnologías periféricas y centrales compatibles con los cambios de procesos. Por ejemplo, la mecanización cada vez mayor de la cosecha de la caña, sin recurrir a la quema previa, derivó en problemas con respecto a las impurezas vegetales y minerales transportadas a los ingenios junto con la caña. Por ese motivo, y con miras al desarrollo de tecnologías ambientalmente correctas que contribuyan a disminuir los costos y acrecentar la productividad, se observa un mayor interés por la limpieza en seco de la caña de azúcar.

Para la limpieza en seco se utiliza un chorro de aire en dirección contraria al flujo de la caña sobre una estera. El aire recoge las impurezas en una cámara, facilitando la separación y el aprovechamiento de la paja para la generación de energía. Además de economizar agua en el lavado de la caña, este proceso garantiza un incremento de la molienda (a diferencia del lavado con agua, no reduce la concentración de sacarosa), separa la paja de la caña antes del pasaje por la molienda, aminora el desgaste de la molienda, mejora la calidad del caldo y amplía la vida útil de los haces tubulares de las calderas, entre otras cosas (JornalCana, 2008b). Con el objetivo de reducir costos y mejorar la calidad de los productos y las condiciones de trabajo, la empresa Gases e Equipamentos Silton Ltda. (Gasil) (con sede en Recife, Pernambuco) creó una nueva tecnología para el tratamiento del caldo en las unidades de fabricación de azúcar y alcohol. En ese nuevo proceso la purificación del azúcar se realiza mediante ozono $\left(\mathrm{O}_{3}\right)$ en lugar de azufre, evitando de ese modo sus efectos perjudiciales en la salud de los trabajadores y el medio ambiente. A partir de un proceso de transformación del oxígeno $\left(\mathrm{O}_{2}\right)$ mediante una descarga eléctrica de alta tensión, cada ingenio puede producir su propio ozono (JornalCana, 2008b). Otra ventaja importante del uso del ozono para la purificación del azúcar es su mayor aceptación en el mercado internacional, habida cuenta de las limitaciones impuestas por la OMC a los productos que incluyen azufre en el proceso productivo (JornalCana, 2008d).

La fermentación, responsable de la transformación de los azúcares contenidos en el caldo de caña en alcohol y una de las principales operaciones de una destilería, también ha sido objeto de mejoramientos. La empresa brasileña Natrontec Estudos e Engenharia de Processos patentó un proceso de fermentación continua, en que se utiliza una levadura floculante. Esa levadura se obtiene mediante la centrifugación de la vinaza, un residuo generado por el propio proceso de fermentación. Los procesos continuos de fermentación no sufren interrupciones. En otras palabras, mientras que el ciclo completo de los procesos discontinuos comprende las etapas de carga, inoculación, fermentación, descarga y limpieza del equipo, en los procesos continuos el "biorreactor" se alimenta constantemente con mosto fresco, que fermenta y se retira también en forma constante. La corriente de extracción es igual a la de alimentación para permitir el flujo continuo del producto.

También se descubrió que el aumento de la concentración alcohólica en el proceso de fermentación puede contribuir en gran medida a la reducción del volumen de vinaza (residuo) en el proceso industrial de producción de etanol. Algunas levaduras permiten una fermentación con niveles del $14 \%$ al $16 \%$, que garantizan una disminución del $50 \%$ en el volumen de vinaza. La Fermatec estudia un proceso de fermentación con una concentración alcohólica del 18\%, que reduciría aún más el volumen de residuos (de 7 litros con una concentración alcohólica del $14 \%$ a 5,5 litros con una concentración del 18\%). No obstante, ese proceso exige la calificación 
de la mano de obra y puede resultar inviable en caso de no contar con ella (JornalCana, 2008c).

En la actualidad se está probando una nueva tecnología, con una unidad de demostración del proceso, que promete duplicar la producción de alcohol sin engrosar la cantidad de caña de azúcar plantada. Esa nueva tecnología —Dedini Hidrólisis Rápida- se está desarrollando en el marco de una colaboración entre la Fundación para la Defensa de las Investigaciones del estado de São Paulo (FAPESP) y el Grupo Dedini. Si este proceso específico de investigación y desarrollo tiene éxito, la producción adicional de etanol celulósico surgirá como un nuevo paradigma tecnológico del sector. El proceso consiste en la transformación del bagazo de caña en azúcares formados por cadenas de seis carbonos (hexosas). La lignina, estructura de la fibra del bagazo de caña que protege la celulosa, se diluye con un solvente que permite también la formación de azúcares a partir de este proceso. Posteriormente esos azúcares se fermentan y destilan mediante los procesos normales utilizados en los ingenios, resultando en una mayor producción —de segunda generación — de alcohol, a partir de un residuo de la producción de primera generación (bagazo) (Perozzi, 2007).

Así, la fermentación de la xilosa (azúcar de la clase de las pentosas) constituye uno de los obstáculos para la producción de etanol de segunda generación (celulósico). Al ser más complejo que la celulosa y la hemicelulosa, la fermentación de ese azúcar requiere el uso de hongos y eso puede encarecer o incluso tornar inviable la generación de etanol celulósico. La mayoría de las empresas productoras de azúcar y alcohol producen sus propias enzimas celulares, lo que garantiza una reducción de hasta 12 veces en los costos de la fermentación (Bastos, 2007; JornalCana, 2008c).

El proceso de hidrólisis enzimática desarrollado por Dedini y FAPESP deberá permitir la utilización de dos tercios de la energía de la caña de azúcar (caldo y bagazo) para producir etanol. El equipo de la Quadex Technology, empresa de Campinas, São Paulo, está investigando alternativas para producir etanol a partir de cualquier material celulósico (bagazo y paja de la caña de azúcar, papel, corteza de árbol, entre otros) mediante el proceso de hidrólisis ácida. La conclusión de esa nueva tecnología garantizaría el aprovechamiento del 100\% del potencial energético de la caña de azúcar en la producción de etanol (JornalCana, 2008c; Perozzi, 2007).

\section{Comercialización y distribución}

Por último, cabe mencionar la fase comercial y de distribución de esta cadena de valor, que también está dominada enteramente por los ingenios, ya sea con respecto a la venta de azúcar y alcohol como a la venta de electricidad a las distribuidoras. Un factor que influye considerablemente en el precio de la mayoría de los productos comercializados en el Brasil es el costo del transporte utilizado para su distribución. En la gran mayoría de los casos se trata de transporte por carretera, que además de caro es lento y de poca capacidad individual. A objeto de reducir el impacto ambiental y también el precio de los productos de la industria del azúcar y el alcohol, las autoridades de PETROBRAS estudian la construcción de tuberías para el alcohol, que vincularían a las regiones productoras con los centros consumidores y los puertos de exportación. La intensificación del transporte ferroviario y acuático también constituye un potencial competidor para la distribución de etanol y azúcar (FAPESP, 2008).

El incremento de la producción de energía eléctrica mediante la cogeneración también resulta limitado por la falta de inversiones en redes de distribución. En muchos ingenios se termina por descartar total o parcialmente el excedente debido a la precaria infraestructura de distribución de energía disponible. Se están realizando inversiones en la capacidad de generación y la red de distribución de este producto para aumentar su comercialización (Souza, 1999; Castro, Dantas y Leite, 2008). La expansión de la demanda de energía en la economía brasileña, debido al crecimiento económico (la elasticidad-ingreso del consumo de electricidad es mayor que la unidad), ha incentivado las inversiones en tecnologías de generación de electricidad correctas desde el punto de vista ambiental.

Las nuevas tecnologías y procesos que permiten la optimización energética pueden emplearse tanto en los ingenios antiguos como en las unidades nuevas, que ya poseen una concepción actualizada con respecto a la necesidad de reducir el consumo de vapor a fin de acrecentar la producción de energía eléctrica. Para que ese ahorro de vapor sea posible es necesario invertir en calderas de alta presión y con capacidad de generación adecuada para el aprovechamiento de la energía excedente (JornalCana, 2008a).

Una inversión bien planificada en cogeneración produce resultados notables en comparación con inversiones en pequeñas mejoras o cambios que afectan a una parte de la capacidad. Dependiendo del grado tecnológico, el potencial varía de 60 kilovatios-hora por tonelada de caña a 80 kilovatios-hora por tonelada de caña, una franja muy amplia (casi 30\%) que puede tener repercusiones decisivas en los resultados de la agroindustria (Procknor, 2007). En el cuadro 3 se presentan algunas opciones de tecnologías y sus respectivos resultados productivos. 


\begin{tabular}{|c|c|c|c|c|c|}
\hline \multirow{2}{*}{$\begin{array}{l}\text { Base: Caldera } 300 \text { toneladas/hora } \\
\text { vapor }\left(66 \text { bar }-480^{\circ} \mathrm{C}\right)\end{array}$} & \multicolumn{5}{|c|}{ Alternativas para el sistema $\left(\mathrm{bar} /{ }^{\circ} \mathrm{C}\right)$} \\
\hline & $66 / 480$ & $68 / 520$ & $92 / 520$ & $100 / 540$ & $120 / 540$ \\
\hline Turborreductor (megawatts) & $2 \times 24,5$ & $2 \times 26,0$ & $2 \times 27,5$ & $2 \times 28,5$ & $2 \times 29,0$ \\
\hline Generador (valor de margen añadido) & $2 \times 30,5$ & $2 \times 32,5$ & $2 \times 34,0$ & $2 \times 35,5$ & $2 \times 36,5$ \\
\hline Combustible (libra vapor/libra bagazo) & 2,23 & 2,16 & 2,18 & 2,15 & 2,17 \\
\hline \multirow[t]{2}{*}{ Potencial generación (megawatts) } & 48,7 & 51,9 & 54,5 & 56,7 & 58,1 \\
\hline & \multicolumn{5}{|c|}{ Inversión (en millones de reales) } \\
\hline Caldera & 39 & 41 & 45 & 46 & 48 \\
\hline Turbogeneradores & 12 & 13 & 14 & 15 & 16 \\
\hline Total & 51 & 54 & 59 & 61 & 63 \\
\hline
\end{tabular}

Fuente: elaboración propia sobre la base de datos de C. Procknor, Coogeração de energia a bagaço de cana do Estado de São Paulo, São Paulo, Assembléia Legislativa do Estado de São Paulo, octubre de 2007.

\section{Agenda estratégica innovadora}

Las grandes innovaciones tecnológicas no solo han contribuido al mantenimiento de la agroindustria de la caña de azúcar, sino también a su desarrollo, inserción y expansión internacional mediante el mejoramiento de los estándares de calidad, el respeto de las normas ambientales, la creciente competitividad por la vía de los precios y la innegable ventaja energética. Existen sin embargo algunos aspectos que podrían promover aún más el crecimiento del sector:

- Programas dirigidos al crecimiento vertical de la producción de caña de azúcar (más producción en la misma área plantada) y mecanismos de almacenamiento estratégico de alcohol, para evitar la fluctuación de los precios y la escasez de la oferta. Esos dos programas ayudarían a contrarrestar las críticas sobre el posible avance del cultivo de caña hacia la Amazonia Legal (que, como se mencionó, son infundadas) y a las áreas destinadas al cultivo de productos alimenticios, mejorando la imagen internacional del sector. A eso también contribuye el estudio agroecológico de la caña de azúcar, aprobado por el gobierno federal, que comprueba la existencia de más de 64 millones de hectáreas aptas para la expansión del cultivo de la caña, excluidas la Amazonia, el Pantanal, las tierras indígenas, las zonas urbanas, los ríos y fuentes, entre otros.

- Es importante mantener o incrementar la competitividad de este sector frente a los competidores internacionales. Para eso se debe garantizar e incentivar el registro de patentes nacionales e internacionales con respecto a las tecnologías brasileñas de producción del alcohol, garantizando la apropiación de eventuales regalías.

- La expansión del uso del etanol también puede acelerarse. Las inversiones en investigación y desarrollo podrían incentivar el uso de ese combustible en los medios de transporte pesados, con miras a sustituir al diésel. Esa medida contribuiría no solo a disminuir la contaminación en los grandes centros urbanos, sino también a reducir el precio del combustible a utilizarse, dado que los responsables de los ingenios podrían emplearlo en el abastecimiento de sus propias máquinas cosechadoras y camiones. En ese sentido, los fabricantes instalados en el país producen motocicletas policarburantes desde inicios de 2009.

- Divulgar la imagen del Brasil como proveedor mundial de vanguardia en agroenergía y soluciones ambientales (alcohol combustible, biodiésel, créditos de carbono, tecnologías limpias, entre otras) beneficiaría al país y favorecería la comercialización de sus productos y servicios. Este esfuerzo garantizaría que el etanol de caña no se confundiera con el proveniente de otras fuentes agrícolas que compiten con los alimentos (como el maíz o la remolacha), y eventualmente aminoraría las restricciones para ingresar en algunos mercados internacionales.

- Los responsables de los ingenios podrían diversificar sus actividades e invertir conjuntamente en 
canales de distribución que garanticen un flujo de etanol mayor y más rápido hacia el mercado interno y externo. Podrían realizarse operaciones conjuntas, con gestión independiente, para entrar definitivamente en el mercado de distribución de etanol, comprando distribuidoras existentes o montando nuevas, que también podrían actuar en el ramo de puestos de combustibles renovables. El Grupo Cosan, que recientemente adquirió la capacidad de distribución de combustibles de Esso en el Brasil, es tal vez un ejemplo de esta tendencia (Scaramuzzo, 2008).

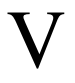

\section{Consideraciones finales}

Antes de pasar por el proceso de desregulación, el sector del azúcar y el alcohol no necesitaba ni poseía incentivos para realizar mayores inversiones en innovaciones que contribuyeran a mejorar su desempeño competitivo y productivo. Entonces, los dirigentes del sector se preocupaban sobre todo de reducir los costos mediante mejoras incrementales derivadas del proceso de aprendizaje práctico.

En 1975, con la creación del Proálcool, la producción de etanol a escala y los incentivos gubernamentales para la expansión de su consumo aumentaron la importancia del sector en la economía nacional. Comenzó de ese modo un proceso que consolidaría al alcohol como fuente de energía renovable en el Brasil. El sector del azúcar y el alcohol cobró impulso con la producción de vehículos a alcohol, la introducción de tecnologías importadas para el incremento de la molienda y el surgimiento de centros de investigación públicos y privados.

Los cambios que tuvieron lugar en la economía brasileña a fines de la década de 1990 pusieron fin al control de las cuotas de producción y los precios de venta de la caña de azúcar, el azúcar y el alcohol. Los propietarios de los ingenios se vieron obligados a buscar nuevas estrategias para protegerse de la competencia y mantener la competitividad de sus productos. Para atender a esa nueva demanda, los centros de investigación públicos (universidades, EMBRAPA) y privados (Copersucar) realizaron crecientes inversiones en actividades de investigación y desarrollo relacionadas con el sector.

En este trabajo se analizó la importancia de dichas inversiones en investigación y desarrollo para la agroindustria y se mencionaron algunas de las barreras que han dificultado la globalización del cultivo de caña de azúcar y del etanol, entre ellas, la falta de conocimiento sobre la composición del etanol y las exigencias internacionales de calidad y sostenibilidad. En consecuencia, es necesario que los dirigentes del sector continúen invirtiendo en investigación y desarrollo y buscando estrategias para acrecentar su rentabilidad, ya sea mediante la reducción de los costos, el aumento de la productividad o el descubrimiento de nuevos mercados - sobre todo extranjeros- que garanticen mayores ingresos, inversiones y exigencias para el desarrollo del sector.
Abarca, C.D.G. (1999), "Inovações tecnológicas na agroindústria da cana de açúcar no Brasil”", Anais da Associação Brasileira de Engenharia de Produção (Engep) [en línea] http://www.abepro. org.br/biblioteca/ENEGEP1999_A0105.PDF.

Assumpção, M.R.P.A. (2004), "Derivados de açúcar: internacionalização na cadeia produtiva do açúcar na segunda metade da década de 1990", O.R. \& A. Revista de administração da UFLA, vol. 6, № 1, Minas Gerais, Universidad Federal de Lavras, enero-junio. (1998), "A dinâmica da cadeia de suprimento no setor sucroalcooleiro", São Carlos, Departamento de Engenharia de Produção (DEP)/Universidad Federal de São Carlos (UFSCar) Grupo de Estudos e Pesquisas Agroindustriais (GEPAI) [en línea] www.agencia.cnptia.embrapa.br/Repositorio/ENEGEP1998_AR T189_000fk4291cb02wyiv80sq982yqc2y714j.pdf
Baccarin, J.G. y R.C. Castilho (2002), "A geração de energia como opção de diversificação produtiva da agroindústria canavieira", documento presentado en el $4^{\circ}$ Encontro de Energia no Meio Rural.

Bastos, V.D. (2007), "Etanol, alcoolquímica e biorrefinarias", BNDES setorial, $\mathrm{N}^{\circ} 25$, Río de Janeiro, Banco de Desarrollo del Brasil, marzo.

BNDES (Banco de Desarrollo del Brasil) (2008), Bioetanol de caña de azúcar: energía para el desarrollo sostenible, Río de Janeiro, Banco de Desarrollo del Brasil/Centro de Gestão e Estudos Estratégicos (BNDES/CGEE).

Bragato, I.R. y otros (2008), "Produção de açúcar e álcool versus responsabilidade social corporativa: as ações desenvolvidas pelas usinas de cana-de-açúcar frente às externalidades negativas", 
Gestão \& produção, vol. 15, No 1 , São Carlos, Universidade Federal de São Carlos, abril.

Castro, N.J., G.A. Dantas y A.L.S. Leite (2008), "Instrumentos para compatibilizar o atrito entre remuneração do MWh sucroalcooleiro e a garantia da modicidade tarifária", Economia y energia, $\mathrm{N}^{\mathrm{o}} 67$, abril-mayo.

Coutinho, L. (1995), "A terceira revolução industrial e tecnológica: as grandes tendências de mudança", Economia e sociedade, $\mathrm{N}^{\circ} 1$, Campinas, Universidade Estadual de Campinas.

Dosi, G. (1988), "Sources, procedures, and microeconomic effects of innovation", Journal of Economic Literature, vol. 26, $\mathrm{N}^{\mathrm{o}} 3$, Nashville, Tennessee, American Economic Association, septiembre.

Eid, F., K. Chan y S.S. Pinto (1998), “Tecnologia e co-geração de energia na indústria sucroalcooleiroa paulista: uma análise da experiência e dificuldades de difusão", Informações econômicas, vol. 28, $\mathrm{N}^{\circ}$ 5, São Paulo, Instituto de Economia Agrícola, mayo.

FAPESP (Fundaçao de Amparo à Pesquisa do Estado de São Paulo) (2008), "Nova fronteira", Pesquisa FAPESP, No 146, São Paulo, abril.

(2007), Brasil: líder mundial em conhecimento e tecnologia de cana e etanol, São Paulo.

(2006), "Revolução no canavial”, Pesquisa FAPESP, No 122, São Paulo, abril.

FIESP (Federación de Industrias del Estado de São Paulo) (2008), Agronegócio brasileiro, São Paulo.

Fronzaglia, T. y R. Martins (2006), "Coordenação de redes de P\&D: o caso de inovação do sistema sucroalcooleiro", documento presentado en el Seminario internacional "Ciência e tecnologia na América Latina", Campinas, Universidad Estadual de Campinas/ Coordenadoria de Relações Institucionais e Internacionais (UNICAMP/CORI).

Gereffi, G., J. Humphrey y T. Surgeon (2005), "The governance of global value chains", Review of International Political Economy, vol. 12, No 1, Londres, Taylor \& Francis, febrero.

Gereffi, G. y M. Korzeniewicz (1994), "Commodity chains and global capitalism", inédito.

Humphrey, J. (2006), Global Value Chains in the Agrifood Sector, Viena, Organización de las Naciones Unidas para el Desarrollo Industrial (ONUDI).

Iannoni, A.P. y R. Morabito (2002), "Análise do sistema logístico de recepção de cana de açúcar: um estudo de caso utilizando simulação discreta", Gestão \& produção, São Carlos, Universidade Federal de São Carlos.

IPEA (Instituto de Investigación Económica Aplicada) (2008), Carta de conjuntura, Río de Janeiro, 2008.

Jank, M.S. (2008), "A cana de açúcar, de etanol e de eletricidade: uma commodity global" [en línea] http://www.unica.com.br/ opiniao/show.asp? $m s g C o d e=\{$ E9866ECF-C573-4370-80C5E0F2E7CF9AF6

JornalCana (2008a), "Hedge e gestão profissional", No 161, mayo. - (2008b), "Etanol pode ser commodity já em 2009”, No 174, junio.

(2008c), "Ações significativas, respostas imediatas", $\mathrm{N}^{\circ} 175$, julio.

(2008d), "Uma janela se abre para o setor", $\mathrm{N}^{\circ} 176$, agosto.

(2007), "Ripalapatrás", $\mathrm{N}^{\circ} 157$, enero.

Kaplinsky, R. (2000), "Spreading the gains from globalisation: what can be learned from value chain analysis?", IDS Working Paper, $\mathrm{N}^{\mathrm{o}} 110$, Brighton, Institute of Development Studies.

Lima, S. (2007), "A nova fronteira do etanol", Exame, septiembre.

Macedo, I.C. (2007), "Situação atual e perspectivas do etanol”, Estudos avançados, vol. 21, $\mathrm{N}^{\circ}$ 59, São Paulo, enero-abril.

Manechini, C., A.R. Junior y J.L. Donzelli (2005), "Benefits and problems of trash left in the field", Biomass Power Generation: Sugar Cane Bagasse and Trash, S.J. Hassuani, M.R.L.V. Assuani e I.C. Macedo, Piracicaba, Programa de las Naciones Unidas para el Desarrollo (PNUD).
Mariotoni, M.A. y A.T. Furtado (2004), "A Organização Mundial do Comércio e as novas oportunidades no mercado internacional para o setor sucroalcooleiro brasileiro" [en línea] http://www. nipeunicamp.org.br/agrener/anais/2004/Trabalho\%20139.pdf.

Michellon, E., A.A.L. Santos y J.R.A. Rodrigues (2008), "Breve descrição do Proálcool e perspectivas futuras para o etanol produzido no Brasil", presentación en el XLVI Congresso da Sociedade Brasileira de Economia, Administração e Sociologia Rural.

Ministério da Agricultura, Pecuária e Abastecimento (2009), Anuário estatístico de agroenergia, Brasilia.

Negrão, L.C.P. y M.L.P. Urban (2005), “Álcool como commodity internacional", Economia \& energia, año 8, № 47, diciembreenero.

Nelson, R.R. y S.G. Winter (1982), An Evolutionary Theory of Economic Change, Cambridge, Massachusetts, Harvard University Press.

(1977), "In search of a useful theory of innovation", Research Policy, vol. 6, $\mathrm{N}^{\mathrm{o}}$ 1, Amsterdam, Elsevier.

(1974), "Neoclassical vs. evolutionary theories of economic growth: critique and prospectus", Economic Journal, vol. 84, No 336, Londres, Royal Economic Society, diciembre.

Neves, M.F. y M.A. Conejero (2007), "Sistema agroindustrial da cana: cenários e agenda estratégica", Economia aplicada, vol. 11, № 4, São Paulo, Universidad de São Paulo, octubre-diciembre.

Pavitt, K. (1984), "Sectoral patterns of technical change: towards a taxonomy and a theory", Research Policy, vol. 13, No 6 , Amsterdam, Elsevier, diciembre.

Pedro, E.S. (2004), "Gestão tecnológica: um estudo de caso no setor sucroalcooleiro", São Carlos, Universidad Federal de São Carlos.

Penrose, E. (1959), The Theory of the Growth of the Firm, Nueva York, Wiley.

Perozzi, M. (2007), "O dobro de álcool na mesma área plantada", Inovação Uniemp, vol. 3, $\mathrm{N}^{\mathrm{o}}$ 2, Campinas, Instituto Uniemp, marzo-abril.

Piacente, E.A. y F.J. Piacente (2004), "Desenvolvimento sustentável na agroindústria canavieira: uma discussão sobre os resíduos" [en línea] http://www.cori.unicamp.br/IAU/completos/ Desenvolvimento $\% 20$ Sustentave1\%20Agroindustria\%20 Canavieira\%20uma\%20discussao $\% 20$ sobre $\% 20$ os $\% 20$ residuos.doc

Possas, M.L. (2003), "Ciência, tecnologia e desenvolvimento: referências para debate", documento presentado en el Seminario "Brasil em desenvolvimento", Río de Janeiro, inédito.

Possas, S. (2006), "Concorrência e inovação", Economia da inovação tecnológica, V. Peláez y T. Szmrecsányi (orgs.), São Paulo, Hucitec.

Procknor, C. (2007), Coogeração de energia a bagaço de cana do Estado de São Paulo, São Paulo, Assembléia Legislativa do Estado de São Paulo, octubre.

Ramos, D.A.R. y J.G. Souza (2003), "As transformações do setor sucroalcooleiro e seus impactos na composição orgânica do capital: uma análise do setor no município de SertãozinhoSP" [en línea] www2.prudente.unesp.br/eventos/semana_geo/ dulcineiarissattiramos.pdf

RFA (Renewable Fuels Association) (2009), "Ethanol helps vehicles run cleaner" [en línea] http://www.ethanolrfa.org/index.php

Rodrigues, R. (2008), "Biocombustível", Cadernos FGV Projetos, año 3, No 7, Río de Janeiro, Fundación Getulio Vargas, noviembre.

(2001), "Bagaço e álcool”, Revista agroanalysis, São Paulo, Associação Brasileira de Agribusiness, diciembre.

Salibe, A.C. (2008), "Sustentabilidade ambiental no Brasil sob perspectiva da indústria", documento presentado en el International Latin American-European Cooperation Workshop on "Sustainability in Biofuel Production [en línea] http://cenbio.iee.usp.br/download/ eventobiotop/Antonio_Salibe-UDOP.pdf. 
Scaramuzzo, M. (2008), "Shell estuda sociedade em usina da Cosan", Valor econômico, 2 de diciembre.

Schumpeter, J.A. (1942), Capitalism, Socialism and Democracy, Londres, G. Allen \& Unwin.

Souza, R.R. (2006), "Oportunidades e desafios para o mercado mundial de álcool automotivo", Río de Janeiro, Universidad Federal de Río de Janeiro.

Souza, Z.J. (1999), "Uma avaliação das formas de comercialização da energia co-gerada pelo setor sucroalcooleiro", Piracicaba.

- (s/f), "Um mercado futuro de eletricidade e o setor sucroalcooleiro: oportunidades de negócio" [en línea] http:// www.nuca.ie.ufrj.br/livro/estudos/souzaum.doc

Stamer, J.M., C. Maggi y S. Seibel (2001), "Cadeia de valor global do setor cerâmico: um estudo comparativo dos clusters de Sassuolo, Castellón e Criciúma", agosto, inédito.

Sturgeon, T. (2006), "Conceptualizing integrative trade: the global value chains framework", documento preparado para la CTPL Conference "Integrative Trade between Canada and the United States - Policy Implications", Ottawa, 6 de diciembre.

(1997), "Does manufacturing still matter? The organizational delinking of production from innovation", Working Paper,
$\mathrm{N}^{\circ}$ 92B, Berkeley Roundtable on the International Economy (BRIE), agosto.

Sturgeon, T. y J.R. Lee (2005), "Industry co-evolution and the rise of a shared supply-base for electronics manufacturing", Global Taiwan: Building Competitive Strengths in a New International Economy, S. Berger y R. Lester (comps.), Armonk, M.E. Sharpe.

Toneto, Jr., R. (2007), "Estudo da competitividade da indústria paulista no setor sucroalcooleiro", Ribeirão Preto, inédito.

ÚNICA (União da Indústria de Cana-de-Açúcar) (2004), Açúcar e álcool do Brasil: commodities da energia e do meio ambiente, São Paulo.

Vian, C.E.F. y W. Belik (2003), "Os desafios para a reestruturação do complexo agroindustrial canavieiro do Centro-Sul”, Economia, vol. 4, No 1, Río de Janeiro, Associação Nacional dos Centros de Pósgraduação em Economia (ANPEC).

Vieira, G. (2003), "Avaliação do custo, produtividade e geração de emprego no corte de cana-de-açúcar, manual e mecanizado, com e sem queima prévia", Botucatu, Universidade Estadual Paulista Julio de Mesquita Filho (UNESP).

Vieira, M.C.A. (2006), "Setor sucroalcooleiro brasileiro: evolução e perspectivas", BNDES setorial, Río de Janeiro, Banco de Desarrollo del Brasil. 